\title{
Does the Phillips Curve Dominant the Fluctuations of Inflation
}

\author{
Chien-Chung Nieh ${ }^{1} \&$ Yi-Jen Fan ${ }^{1}$ \\ ${ }^{1}$ Department of Banking and Finance, Tamkang University, Taiwan \\ Correspondence: Chien-Chung Nieh, Department of Banking and Finance, Tamkang University, No. 151, \\ Yingzhuan Rd., Tamsui Dist., New Taipei City 25137, Taiwan (R.O.C.). Tel: 886-2-2621-5656. E-mail: \\ ian2012.fan@gmail.com
}

Received: June 4, 2012

Accepted: July 24, 2012

Online Published: September 3, 2012

doi:10.5539/ibr.v5n10p65

URL: http://dx.doi.org/10.5539/ibr.v5n10p65

\begin{abstract}
We used the panel smooth transition regression (PSTR) model to investigate whether the relationship between inflation and macro variables remain consistent and identify the macro variables that dominate the fluctuations of inflation based on the uncertainty of interest rates and exchange rates for G7 over the period from 19841Q to 20114Q. The results of the empirical tests show that the real activity variables have superior explanatory power to CPI than unemployment rates based on the volatility of interest rates. The real activity variables have greater exploratory power to CPI because the volatility of the exchange rate is over than $40.95 \%$.
\end{abstract}

Keywords: Phillips curve, CPI, PSTR model

\section{Introduction}

We investigated the macro variables that dominate inflation based on the volatility of interest rates and exchange rates. The question we want to know whether the unemployment rate, which is used as an explanatory variable to CPI in the traditional Phillips theory, has a persistent influence on inflation. Moreover, we empirically investigated whether the other main driving factors of inflation and sustainability change based on the uncertainty of the interest rate and exchange rate. We applied the PSTR model to estimate the relationship between macro variables and inflation in G7 countries.

Inflation remains a crucial issue worldwide. Therefore, a number of negative factors cause volatility in inflation, such as oil price; commodity prices are strictly monitored by the ruling authority of countries. The issues regarding inflation are being addressed in macroeconomics; however, the results are inconsistent. Since the Phillips curve was first proposed in 1958, it has been applied in several studies to address the trade-off relationship between the inflation rate and unemployment rate to create policies and forecast inflation. Consistent with the findings of the Phillips curve, Blinder (1997) indicated that the unemployment rate is a suitable factor to explain inflation. Similar findings were obtained by Tella et al. (2001), Meltzer (2006), Zaman et al. (2011), and Doh (2011).

We examined whether the relationship between inflation and macro variables will remain stable based on the uncertainty of the interest rate and exchange rate. To distinguish from prior studies, which often examined a time breakpoint in the regression, we applied PSTR modeling to account for a change of regime in the determinants of the variations of inflation.

The remainder of this paper is organized as follows: Section 2 presents a review of some relevant literature. Section 3 presents the characteristics of the data; Section 4 presents the methodology used to construct the measures in our empirical tests; Section 5 presents the statistical tests to control the interest rate and exchange rate as a threshold; and lastly, Section 6 provides a summary and conclusion.

\section{Literature Review}

To observe the response of CPI to aggregate demand and aggregate supply shocks, Blanchard (1989) showed that the change of aggregate demand and aggregate supply shocks push the price in the short-term and long-term, respectively. Stock and Watson (1999) indicated that real activity and economic indicators have a higher explanatory power to CPI than the unemployment rate. However, Atkeson and Ohanian (2001) obtained contrasting results. Bagliano and Morana (2003), Gerlach and Yiuc (2004), Kemalc (2006), Ribba (2006), 
Gachet et al. (2008), and Liu and Jansen (2011) found that both aggregate supply (monetary supply) and aggregate demand play a dominant role in the determination of inflation. Cheng and Tan (2002) and Haque and Qayyum (2006) showed that central banks worldwide investigate the origins of variations in inflation to create monetary policies. Mallik and Chowdhury (2011) conducted an empirical test to verify that powerful monetary policies can reduce the variation in inflation. Owen and Palmer (2012) proposed that the volatility of exchange rates has a negative effect on inflation. Similar empirical tests were conducted by Brun-Aguerre et al. (2012), Büttner and Hayo (2012), Zhou (2013), Bahmani-Oskooe et al. (2013), and Yilmazkuday (2013).

Past inflation rate information can be used as an adaptive factor to forecast future inflation rates, as proposed by Jacobs and Jones (1980). Other studies, including Mullineaux (1980), Tella et al. (2001), and Cogley and Sbordone (2008) also indicated that the influence of the series of distributed lags of past prices on future inflation rates is statistically significant.

Based on the real balance effect, Benderly and Zwick (1985) indicated that stock returns are not closed to the rate of inflation in the long-term. To incorporate variables related to real activity, which includes real consumption, real investment, and current account, Mallick and Mohsin (2010) proposed that the correlation between real activity and inflation is consistent. Mallik and Chowdhury (2011) indicated that government expenditure is a critical factor to the violation of the inflation rate. Several studies have provided evidence of the effect of the external environment on inflation. Goodman and McMahon (1979) found that oil price increases 0.9 percent and could resulting in increasing 0.6 percentage to 0.7 percentage points to the inflation rate. Using various samples for empirical tests, McGuire and Willman (1999), Roeger (2005), Ajuzie and Ike (2009), and Bachmeier and Cha (2011) indicated that the fluctuations of oil prices have a significant effect on CPI.

Another crucial issue for CPI is to determine whether the relationship between inflation and variables remain stable in the long-term. Consistent with the findings of Phillips (1958), Blinder (1997) indicated that the tradeoff relationship between CPI and unemployment does not change over time. A number of studies estimated the empirical results to achieve an opposing conclusion. Stock and Watson (1999) used the United States data as the sample, and indicated that a stable tradeoff relationship did not exist. Razin and Yuen (2002), Matheson (2008), and Ormerod et al. (2013) obtained the same results under different scenarios.

\section{Data and Summary Statistics}

Our investigation used balanced panel data for a sample of G7 countries (Canada, France, Germany, Italy, Japan, the United Kingdom, and the United States) for the period from 1984:1Q to 2011:4Q. The sources of our sample were obtained from the "DATASTREAM" database.

We gathered variables related to the fluctuations of CPI from related studies, such as Goodman and McMahon (1979), Blanchard (1989), Stock and Watson (1999), and Haque and Qayyum (2006). In addition to the unemployment rate, we used the industrial production index, government expenditure, and ratio of real trade balance to GDP as the proxy for real activity, which were calculated as annual percentages and denoted as $I P_{i t}, G O V_{i t}, T B_{i t}$, respectively. The annual percentage change of money supply was measured as the proxy for monetary instrument. We also included the volatility of oil price (WTI), which is frequently related to CPI $\left(V_{\text {OIL }}\right)$ (Note1), and $\Delta \pi_{i t}\left(\Delta \pi_{i t}\right.$ is the difference between the $\pi_{i t}$ and $\pi_{i, t-1}$, which reflects information regarding past changes of inflation). We explored whether the dominant factors of inflation are stable based on the uncertainty of the interest rate $\left(V I R_{i t}\right)$ and exchange rate $\left(V E R_{i t}\right)$ (Note 2). The average annual percentage change of the industrial production index (1\%) was lower than the average speed of inflation rate $(2.47 \%)$ for G7 from 1984 to 2011, as shown in Table 1. The average unemployment rate was 7.35\%. It implies that the inflation rate increased in conjunction with the unemployment rate in the low-growth economy during the studied period. Table 1 also shows the value of average government expenditure (14.35\%) and average percentage change of money supply (7.19\%). It indicates that the governments of G7 preferred an easy policy over the period to stimulate the economy. 
Table 1. Summary statistics of G7 countries

\begin{tabular}{lllllllllll}
\hline & $\pi_{i t}$ & $U N P_{i t}$ & $I P_{i t}$ & $G O V_{i t}$ & $T B_{i t}$ & $\Delta \pi_{i t}$ & $M S_{i t}$ & $V O I L_{t}$ & $V I R_{i t}$ & $V E R_{i t}$ \\
\hline Mean & 2.47 & 7.35 & 0.01 & 14.35 & -5.38 & -0.04 & 7.19 & 8.39 & 0.65 & 3.43 \\
Median & 2.15 & 7.76 & 0.02 & 5.28 & -0.12 & -0.01 & 6.85 & 4.67 & 0.52 & 2.53 \\
Maximum & 11.44 & 12.70 & 0.30 & 1141 & 85.21 & 3.10 & 32.15 & 69.80 & 4.25 & 26.65 \\
Minimum & -2.23 & 2.17 & -0.33 & -89.9 & -795 & -3.69 & -9.21 & 0.52 & 0.00 & 0.20 \\
Std. Dev. & 1.86 & 2.18 & 0.05 & 63.62 & 48.89 & 0.59 & 5.12 & 11.02 & 0.62 & 3.16 \\
Skewness & 0.93 & -0.61 & -1.37 & 11.76 & -12.5 & -0.42 & 0.65 & 3.72 & 1.65 & 2.97 \\
Kurtosis & 4.84 & 2.61 & 10.11 & 177.5 & 188.7 & 7.15 & 4.94 & 18.71 & 6.87 & 16.07 \\
\hline
\end{tabular}

Notes: This table shows the descriptive statistics of the annual percentage change of CPI $\left(\pi_{i t}\right)$, annual percentage change of unemployment rate $\left(U N P_{i t}\right)$, annual change of industrial production index $\left(I P_{i t}\right)$, annual percentage change of government expenditure $\left(G O V_{i t}\right)$, annual percentage change of real trade balance to GDP ratio $\left(T B_{i t}\right)$, the differential of the CPI $\left(\Delta \pi_{i t}\right)$, annual percentage change of money supply $\left(M S_{i t}\right)$ (Note 3).volatility of WTI oil price $\left(V O I L_{t}\right)$, volatility of discount rate $\left(V I R_{i t}\right)$, and volatility of exchange rate $\left(V E R_{i t}\right)$. The G7 countries refer to Canada, France, the United States, Germany, Italy, Japan, and the United Kingdom.

\section{Methodology}

This section presents the two-regime PSTR approach, a non-dynamic panel model, developed by González et al. (2005). The general PSTR model is defined as follows:

$$
y_{i t}=\mu_{i}+\alpha_{0}^{\prime} x_{i t}+\alpha_{1}^{\prime} x_{i t} h\left(q_{i t} ; \gamma, c\right)+\varepsilon_{i t}
$$

where $i=1, \ldots, N$, and $t=1, \ldots, T . \quad y_{i t}$ is the dependent variable, $x_{i t}$ is the k-dimensional vector of explicative variables, $\mu_{i}$ proxies the fixed individual effect, and the error term is denoted by $\varepsilon_{i t}$. The transition function $h\left(q_{i t} ; \gamma, c\right)$ is a continuous and bounded function of the transition variable $q_{i t}$. The transition function $h\left(q_{i t} ; \gamma, c\right)$ is bounded between 0 and 1 , and is a continuous function of the observable variable $q_{i t}$. Its cumulative distribution function is derived by the following formula:

$$
h\left(q_{i t} ; \gamma, c\right)=\frac{1}{1+e^{-\gamma\left(q_{i t}{ }^{-c}\right)}}, \gamma>0
$$

Following the work of Granger and Teräsvirta (1993), González et al. (2005) considered the following logistic transition function:

$$
h\left(q_{i t} ; \gamma, c\right)=\left[1+\exp \left(-\gamma \prod_{j=1}^{m}\left(q_{i t}-c_{j}\right)\right]^{-1} \quad \text { with } \gamma>0 \text { and } c_{1} \leq \ldots \leq c_{m}\right.
$$

where $c=\left(c_{1}, \ldots, c_{m}\right)^{\prime}$ is an m-dimensional vector of the location parameters, and the slope of transition function is denoted by $\gamma$, which determines the smoothness of the transitions.

Generally, $m=1$ or $m=2$ is sufficient, because these values allow for the commonly encountered types of variation in the parameters (Note 4). For $m=1$, the model implies that the two extreme regimes are associated with low and high values of $q_{i t}$. When $\gamma \rightarrow \infty$, the logistic transition function $h\left(q_{i t} ; \gamma, c\right)$ becomes an indicator function $I[A]$, which has a value of 1 when Event A occurs; otherwise, the value is 0 . Thus, the PSTR model in (1) is the same as the two-regime panel threshold model (Hansen, 1999). For $m=2$, the transition function has a minimum of $\left(c_{1}+c_{2}\right) / 2$ and a value of 1 for both low and high values of $q_{i t}$. Therefore, if $\gamma \rightarrow \infty$, the model becomes a three-regime threshold model. Finally, for any value of $m$, the transition function (3) becomes constant when $\gamma \rightarrow 0$, in which case the model is reduced to a homogenous or linear fixed effects panel regression.

González et al. (2005) generalized the PSTR model to allow more than two different regimes, and constructed the additive model as follows:

$$
y_{i t}=\mu_{i}+\alpha_{0}^{\prime} x_{i t}+\sum_{j=1}^{r} \alpha_{j}^{\prime} x_{i t} h_{j}\left(q_{i t}^{(j)} ; \gamma_{j}, c_{j}\right)+\varepsilon_{i t}
$$


where the transition functions $h_{j}\left(q_{i t}^{(j)} ; \gamma_{j}, c_{j}\right), j=1, \ldots, r$, are of the logistic type (2). The PSTR model building procedure consists of specification, estimation, and evaluation stages. The specification includes testing homogeneity and selecting the transition variable $q_{i t}$. A nonlinear least square method is the first step of the test procedure, which examines the linearity against the PSTR model. If the tests fail to show homogeneity, (3) is used to determine the appropriate form of transition function, that is, the proper value of $\mathrm{m}$.

The estimated model was subjected to misspecification tests to examine whether it provides an adequate data description during the evaluation stage. Parameter constancy, remaining heterogeneity, and autocorrelation of the errors were included at the null hypotheses test. The number of regimes in the panel model must be determined in the final step, that is, a value must be selected for $r$ in (4) (Note5).

We used two "candidates"; that is, the moving average standard deviation of the percentage change of discount rate for each country (Model A, if $q_{i t}^{j}=V I R_{i t}^{j}$ ) and the moving average standard deviation of the percentage change of effective exchange rate for each country (Model B, if $q_{i t}^{j}=V E R_{i t}^{j}$ ). We set up two panel smooth transition regressions, Model A and Model B, as follows:

$$
\begin{gathered}
\pi_{i t}=\mu_{i}+\sum_{i=0}^{6} \alpha_{i}^{\prime} X_{i t}+\sum_{i=0}^{6} \sum_{j=1}^{r} \beta_{i}^{\prime} h_{j}\left(q_{i t}^{j} ; \gamma, c\right) \\
X_{i t}=f\left(U N P_{i t}, I P_{i t}, G O V_{i t}, T B_{i t}, \Delta \pi_{i t}, M S_{i t}, V O I L_{t}\right)
\end{gathered}
$$

Model A:

$$
\pi_{i t}=\mu_{i}+\sum_{i=0}^{6} \alpha_{i}^{\prime} X_{i t}+\sum_{i=0}^{6} \sum_{j=1}^{r} \beta_{i}^{\prime} h_{j}\left(V I R_{i t}^{j} ; \gamma, c\right)
$$

Model B:

$$
\pi_{i t}=\mu_{i}+\sum_{i=0}^{6} \alpha_{i}^{\prime} X_{i t}+\sum_{i=0}^{6} \sum_{j=1}^{r} \beta_{i}^{\prime} h_{j}\left(V E R_{i t}^{j} ; \gamma, c\right)
$$

where $\pi_{i t}$ is the annual percentage change of the inflation rate for each country. The unemployment rate in each country is denoted as $U N P_{i t}$ The variables of $I P_{i t}, T B_{i t}$, and $G O V_{i t}$, are proxies of the real activity; where $I P_{i t}$ is the annual percentage change of the industrial production index for each country, $G O V_{i t}$ is the annual percentage change of government expenditure for each country, and $T B_{i t}$ is the annual percentage change of the ratio of trade balance to GDP for each country. $\Delta \pi_{i t}$ is the difference between the $\pi_{i t}$ and $\pi_{i, t-1}$, which reflects information about past changes of inflation). The annual percentage change of monetary supply for each country was used as a proxy of the monetary instrument $\left(M S_{i t}\right)$. The measurement of oil risk was conducted using the moving average standard deviation of the percentage change of WTI oil spot prices $\left(V O I L_{t}\right)$. We used the volatility of interest rate $\left(V I R_{i t}\right)$ and volatility of exchange rate $\left(V E R_{i t}\right)$ as the candidates for the threshold variables.

\section{Empirical Results}

\subsection{Panel Unit Root Tests}

We used panel data as the sample, which included both time series and cross section. To improve the low power of traditional unit test used univariate tests, we selected Im et al. (IPS test; 2003) and Levin et al. (LLC test; 2002) as stationary tests. As shown in Table 2, the test results indicate that we rejected the null hypothesis of unit root for each variable, which ensures an $\mathrm{I}(0)$ type series. 
Table 2. Panel unit root tests

\begin{tabular}{|c|c|c|c|c|}
\hline & \multicolumn{2}{|r|}{ LLC } & \multicolumn{2}{|r|}{ IPS } \\
\hline & Intercept & Intercept\&Trend & Intercept & Intercept\&Trend \\
\hline$\pi_{i t}$ & $-1.3943^{*}$ & 0.0521 & $-2.2032 * *$ & $-1.5216^{*}$ \\
\hline$U N P_{i t}$ & $-2.9519 * * *$ & -0.0140 & $-1.2598^{*}$ & 3.3330 \\
\hline$I P_{i t}$ & 0.4086 & 1.7311 & $-5.3135 * * *$ & $-5.1953 * * *$ \\
\hline$G O V_{i t}$ & -0.7227 & $-1.6350^{*}$ & $-4.9061 * * *$ & $-5.0516^{* * *}$ \\
\hline$T R_{i t}$ & $-4.8202 * * *$ & $-5.2219 * * *$ & $-7.2424 * * *$ & $-6.5441 * * *$ \\
\hline$\Delta \pi_{i t}$ & $-11.4951 * * *$ & $-12.1636^{* * *}$ & $-14.9327 * * *$ & $-14.5291^{* * *}$ \\
\hline$M S_{i t}$ & $-3.4030 * * *$ & $-2.1778^{* * *}$ & $-5.3037 * * *$ & $-4.6107^{* * *}$ \\
\hline VOIL $_{t}$ & $-6.4509 * * *$ & $-8.0229 * * *$ & $-6.4271 * * *$ & $-7.0502 * * *$ \\
\hline$V O I R_{i t}$ & $-10.5606^{* * *}$ & $-15.3550 * * *$ & $-9.6923 * * *$ & $12.1860^{* * *}$ \\
\hline$V O E X_{i t}$ & $-10.4012^{* * *}$ & $-12.2931^{* * *}$ & $-10.0267 * * *$ & $-10.1197^{* * *}$ \\
\hline
\end{tabular}

Notes: $\pi_{i t}$ indicates the annual percentage change of CPI, $\left(U N P_{i t}\right)$ denotes the annual percentage change of unemployment rate, $\left(I P_{i t}\right)$ denotes the annual change of industrial production index, $\left(G O V_{i t}\right)$ denotes the annual percentage change of government expenditure, $\left(T B_{i t}\right)$ denotes the annual percentage change of real trade balance to GDP ratio, $\left(\Delta \pi_{i t}\right)$ denotes the differential of the CPI, $\left(M S_{i t}\right)$ denotes the annual percentage change of money supply volatility of WTI oil price $\left(V O I L_{t}\right),\left(V I R_{i t}\right)$ denotes the volatility of the discount rate, and $\left(V E R_{i t}\right)$ denotes the volatility of the exchange rate. LLC and IPS represent the panel root techniques by Levin et al. (2002) and Im et al. (2003), respectively. The coefficients differ significantly from zero at the $1 \%, 5 \%$, and $10 \%$ levels, as denoted by $* * *$, **, and $*$, respectively.

\subsection{Homogeneity Test}

Before starting the process of the PSTR test, we examined the linear model against a nonlinear model (a single threshold model). If the null hypothesis was rejected, a single threshold model was estimated and tested against a double threshold model. The process continued until the hypothesis of no additional threshold was not rejected. We applied the LM test of homogeneity of the coefficients of PSTR models, assuming that response of the percentage change of CPI to macro variables does not change across countries. Table 3 shows the results of the linearity and specification tests of no remaining nonlinearity. It reveals that both Model A and Model B rejected the null hypothesis $(r=0)$ and did not reject the null hypothesis $(r=1)$.

Table 3. Wald tests (LM) for Remaining Nonlinearity

\begin{tabular}{lllll}
\hline Model & Model A & \multicolumn{3}{l}{ Model B } \\
\hline Threshold Variable & VOIR $_{i t}$ & & VOEX $_{i t}$ & \\
Number of Location Parameters & $m=1$ & $m=2$ & $m=1$ & $m=2$ \\
$H_{0}: r=0$ vs $H_{1}: r=1$ & $118.568^{* * *}$ & $133.582^{* * *}$ & $184.794^{* * *}$ & $266.474^{* * *}$ \\
& $(0.000)$ & $(0.000)$ & $(0.000)$ & $(0.000)$ \\
$H_{0}: r=1$ vs $H_{1}: r=2$ & 8.508 & 14.061 & 10.848 & 20.266 \\
& $(0.290)$ & $(0.445)$ & $(0.145)$ & $(0.122)$
\end{tabular}

Notes: For each model, the testing procedure was conducted as follows: first, the linear model $(r=0)$ was tested against a model with one threshold ( $r=1$ ). If the null hypothesis was rejected, the single threshold model was tested against a double threshold model $(r=2)$. The procedure continued until the hypothesis of no additional threshold was not rejected. The corresponding LM statistic had an asymptotic $x^{2}(m k)$ distribution under the null hypothesis, where $m$ is the number of location parameters and $k$ is the number of explicative variables, that is, $k=2$ in our specifications. The corresponding probability values are in parentheses. The coefficients differ significantly from zero at the $1 \%, 5 \%$, and $10 \%$ levels, as denoted by $* * *, * *$, and $*$, respectively.

\subsection{Determine the Number of Location Parameters}

Based on the results of the LM test, the following step is to select the optimal number of location parameters for the transition functions. We selected $(\mathrm{m}=1, \mathrm{r}=1)$ and $(\mathrm{m}=1, \mathrm{r}=1)$ as the optimal combinations of Model A and Model B, respectively, based on both AIC and SBC. The detailed information is shown in Table 4. 
Table 4. Determination of the Number of Location Parameters

\begin{tabular}{|c|c|c|c|c|}
\hline Model & Model A & & Model B & \\
\hline Threshold Variable & $\mathrm{VOI}_{i t}$ & & $\operatorname{VOEX}_{\text {it }}$ & \\
\hline Number of Location Parameters & $m=1$ & $m=2$ & $m=1$ & $m=2$ \\
\hline Optimal Number of Thresholds $r^{*}(m)$ & 1 & 1 & 1 & 1 \\
\hline Residual Sum of Squares & 1444.025 & 362.934 & 1124.634 & 1127.410 \\
\hline AIC & 0.7122 & 0.7157 & 0.4622 & 0.4687 \\
\hline SBC & 0.8102 & 0.8198 & 0.5602 & 0.5728 \\
\hline
\end{tabular}

Notes: For each model, the optimal number of locations parameters in the transitions functions can be determined as follows: for each value of $\mathrm{m}$, the corresponding optimal number of thresholds, denoted by $r^{*}(\mathrm{~m})$, is determined according to a sequential procedure based on the $L M_{F}$ statistics of the hypothesis of non remaining nonlinearity. Thus, for each couple $\left(m, r^{*}\right)$, the value the RSS of the model is reported. The total number of parameters is determined by the formula $\mathrm{k}(\mathrm{r}+1)+\mathrm{r}(\mathrm{m}+1)$, where $k$ denotes the number of explicative variables, that is, $k=2$ in our specifications.

\subsection{Parameter Estimate for the PSTR Models}

As shown in Table 5, the coefficients between the inflation rate and macro variables change according to the uncertainty of the discount rate and exchange rate. This implies that the relationship between the Phillips curve of the unemployment rate or real activity variables $\left(I P_{i t}, G O V_{i t}, T R_{i t}\right)$, which depend on the volatility of the interest rate or exchange rate, will be unstable. The findings of the empirical test are consistent with those of Ghironi and Giavazzi (1998), Stock and Watson (1999), Razin and Yuen (2002), Matheson (2008), and Ormerod et al. (2013).

Table 5. Parameter Estimates for the PSTR Models

\begin{tabular}{|c|c|c|c|c|}
\hline Model & Model A & & Model B & \\
\hline Threshold Variable & $\mathrm{VIR}_{i t}$ & & $\mathrm{VER}_{i t}$ & \\
\hline$\left(m, r^{*}\right)$ & $(1,1)$ & & $(1,1)$ & \\
\hline Variables & Coefficient & Standard error & Coefficient & Standard error \\
\hline$\alpha_{0}$ & -0.0769 & 0.0585 & $0.5066 * * *$ & 0.0713 \\
\hline$\alpha_{1}$ & $2.8914 * * *$ & 1.4370 & 2.3003 & 1.9968 \\
\hline$\alpha_{2}$ & -0.5715 & 0.0007 & 0.0000 & 0.0007 \\
\hline$\alpha_{3}$ & 1.1160 & 0.0070 & 0.0008 & 0.0010 \\
\hline$\alpha_{4}$ & $2.7730 * * *$ & 0.1538 & $0.4459 * * *$ & 0.1409 \\
\hline$\alpha_{5}$ & -3.5621 & 0.0125 & $-0.0256^{*}$ & 0.0139 \\
\hline$\alpha_{6}$ & $4.1086^{* * *}$ & 0.3283 & $1.8091^{* * *}$ & 0.2488 \\
\hline$\beta_{0}$ & $0.0978^{* * *}$ & 0.0350 & $-0.3392 * * *$ & 0.0755 \\
\hline$\beta_{1}$ & $-7.3139 * *$ & 3.5099 & 2.7858 & 2.4740 \\
\hline$\beta_{2}$ & $0.0371^{* * *}$ & 0.0086 & $0.3325^{* * *}$ & 0.0333 \\
\hline$\beta_{3}$ & -0.0061 & 0.0073 & -0.0166 & 0.0579 \\
\hline$\beta_{4}$ & -0.3145 & 0.2646 & -0.1736 & 0.1972 \\
\hline$\beta_{5}$ & $0.1408^{* * *}$ & 0.0253 & 0.0191 & 0.0184 \\
\hline$\beta_{6}$ & $-0.9006 *$ & 0.4812 & $-1.1204 * * *$ & 0.3417 \\
\hline c & 0.6785 & & 0.4095 & \\
\hline$\gamma$ & 4.9092 & & 341.9490 & \\
\hline
\end{tabular}

Note: standard errors in parentheses are corrected for heteroskedasticity. For each model and each value of $m$, the number of transition functions $r$ is determined by a sequential testing procedure (Table 4). For each transition function, the estimated location parameters $c_{j}$ and the corresponding estimated slope parameter $\gamma_{j}$ are reported. The PSTR parameters cannot be directly interpreted as elasticities. *, **, and *** denote significance at $10 \%, 5 \%$ and $1 \%$ levels, respectively. 
The findings shown in Table 5 and Table 6 indicate that all real activity variables, money supply side, the differential of inflation, and the volatility of the oil price have a higher influence on CPI than unemployment based on the uncertainty condition of discount rate in low and high regimes. The findings are consistent with those of Stock and Watson (1999). The relationship between the volatility of the oil price and CPI was most consistent in the low regime (the volatility of the discount rate was lower than 67.85\%) and the percentage change of government expenditure dominated the fluctuations of CPI in the high regime. This implies that the volatility of the oil price has a direct and significant influence on CPI, especially in a stable economy (low volatility of discount rate implies that governments are not eager to eliminate the factors that negatively affect the economy). This is supported by the importance of commodity prices at present. By contrast, the government may impalement more aggressive actions, such as adjusting the interest rate or increasing government expenditure to reduce the effect of the mainstream to stabilize the economy. Additional information shown in Table 6 indicates that the tradeoff relationship will disappear in the high regime $(\mathrm{C}>67.85 \%)$; the government may implement alternative actions to reduce the negative influence, such as CPI.

Table 6. Parameter Estimates for Model A

\begin{tabular}{lll}
\hline & $\pi_{i t}=\mu_{i}+\sum_{i=0}^{6} \alpha_{i} X_{i t}+\sum_{i=0}^{6} \sum_{j=1}^{r} \beta_{i}{ }^{\prime} h_{j}\left(V I R_{i t}^{j} ; \gamma, c\right)$ \\
\hline Threshold Variable & $\mathrm{VIR} R_{i t}$ & High Regime (C>67.85\%) \\
Regime (C) & Low Regime $(\mathrm{C}<67.85 \%)$ & 0.0209 \\
$U N P_{i t}$ & -0.0769 & \\
Real Activity Variables & & 0.8076 \\
$I P_{i t}$ & 2.8914 & 3.7668 \\
$G O V_{i t}$ & -0.5715 & 0.2835 \\
$T R_{i t}$ & 1.1160 & \\
Past inflation information & & 1.5445 \\
$\Delta \pi_{i t}$ & 2.7730 & 2.0092 \\
Money Supply Side & & \\
$M S_{i t}$ & -3.5621 & 2.2369 \\
External impulse & 4.1086 & \\
$V O I L_{t}$ & &
\end{tabular}

Note: For each model and each value of $m$, the number of transition functions $r$ is determined by a sequential testing procedure (Table 4). For each transition function, the estimated location parameters $c_{j}$ and the corresponding estimated slope parameter $r_{j}$ are reported.

We analyzed the relationship between CPI and macro variables based on the volatility of the exchange rate from Model B (Table 7). Our findings indicate that the coefficient of all macro variables related to the percentage of CPI is unstable, which is consistent with the results from Model A. The results of our test indicate that the annual percentage of the industrial production index and the volatility of the oil price have higher explanatory power to CPI than the unemployment rate when the volatility of the exchange rate is higher than $40.95 \%$. Both government expenditure and differential inflation are close to the fluctuation of CPI when the uncertainty risk of the exchange rate increases. As shown in Table 7, only the real activity macro is close to violation of the CPI. The exchange rate is an indicator of international competition. Regardless of the factors that push the violation of the exchange rate, the domestic economy is more unstable in contrast to the lower violation of the exchange rate. The exchange rate has a significant influence on domestic industry and policy direction. A possible explanation for our findings is that the unstable exchange rate results in violating price and increasing difficulties in controlling cost for real activity producers and government expenditure. The external environment violation reflects the production cost and influences market pricing. In other words, variations in the real activity result in violating the CPI indirectly. 
Table 7. Parameter Estimates for Model B

\begin{tabular}{|c|c|c|}
\hline \multicolumn{3}{|c|}{$\pi_{i t}=\mu_{i}+\sum_{i=0}^{6} \alpha_{i}^{\prime} X_{i t}+\sum_{i=0}^{6} \sum_{j=1}^{r} \beta_{i}^{\prime} h_{j}\left(V E R_{i t}^{j} ; \gamma, c\right)$} \\
\hline Threshold Variable & $\mathrm{VER}_{i t}$ & \\
\hline Regime (C) & Low Regime $(\mathrm{C}<40.95 \%)$ & High Regime (C>40.95\%) \\
\hline $\mathrm{UNP}_{i t}$ & 0.5066 & 0.1674 \\
\hline \multicolumn{3}{|c|}{ Real Activity Variables } \\
\hline $\mathrm{IP}_{i t}$ & 2.3003 & 5.0861 \\
\hline $\mathrm{GOV}_{i t}$ & 0.0000 & 0.3325 \\
\hline $\mathrm{TR}_{i t}$ & 0.0008 & -0.0158 \\
\hline \multicolumn{3}{|c|}{ Past inflation information } \\
\hline$\Delta \pi_{i t}$ & 0.4459 & 0.2723 \\
\hline \multicolumn{3}{|l|}{ Money Supply Side } \\
\hline $\mathrm{MS}_{\text {it }}$ & -0.0256 & -0.0065 \\
\hline \multicolumn{3}{|l|}{ External impulse } \\
\hline VOIL $_{t}$ & 1.8091 & 0.6887 \\
\hline
\end{tabular}

Note: The coefficients of variables in high regime are equal to $\left(\alpha_{i}+\beta_{i}\right)$. For each model and each value of $m$ the number of transition functions $r$ is determined by a sequential testing procedure (see Table4). For each transition function, the estimated location parameters $c_{j}$ and the corresponding estimated slope parameter $\gamma_{j}$ are reported.

\section{Summary and Conclusion}

Inflation issues have become a crucial topic in macroeconomics since Phillips (1958) proposed that the unemployment rate is an excellent factor to explain the CPI. Those findings were disputed in several studies using various data and variables. We used the PSTR model, which can be used to discuss whether the coefficients between independent variables and dependent variables vary based on the uncertainty of the discount rate or exchange rate, to reexamine the factors that have a significant influence on the violation of CPI.

The results of our empirical tests show that the coefficients between CPI and macro variables are inconsistent based on the volatility of the discount rate or the exchange rate. We also verified that the mainstream fluctuations of CPI are influenced by real activity variables based on the volatility of the interest rate. When the volatility of the interest rate was lower than $67.85 \%$, the main violation of CPI resulted from the volatility of the oil price; government expenditure has a higher exploratory power to CPI than other variables when the volatility of the interest rate is higher than $67.85 \%$. The results also show that the importance of real activity on the violation of CPI cannot be ignored when the volatility of the exchange rate is higher than $40.95 \%$. Compared to other macro variables, the annual percentage change of the industrial production index has excellent explanatory power for the fluctuation of CPI.

\section{References}

Ajuzie, E. I. S., \& Ike, R. M. (2009). Oil speculation: The impact on prices, inflation, interest rates and the economy. Journal of Business and Economics Research, 7(10), 59-67.

Atkeson, A., \& Ohanian, L. E. (2001). Are phillips curves useful for forecasting inflation?. Federal Reserve Bank of Minneapolis. Quarterly Review - Federal Reserve Bank of Minneapolis, 25(1), 2-11.

Bachmeier, L. J., \& Cha, I. (2011). Why dont oil shocks cause inflation? evidence from disaggregate inflation data. Journal of Money, Credit, and Banking, 43(6), 1165-1183. http://dx.doi.org/10.1111/j.1538-4616.2011.00421.x

Bagliano, F. C., \& Morana, C. (2003). Measuring US core inflation: A common trends approach. Journal of Macroeconomics, 25(2), 197-212. http://dx.doi.org/10.1016/S0164-0704(03)00025-9

Bahmani-Oskooee, M., Hegerty, S. W., \& Xu, J. (2013). Exchange-rate volatility and US-Hong Kong industry trade: Is there evidence of a third country effect?. Applied Economics, 45(18), 2629-2651. http://dx.doi.org/10.1080/00036846.2012.654918 
Benderly, J., \& Zwick, B. (1985). Inflation, real balances, output, and real stock returns. The American Economic Review, 75(5), 1115-1123. http://dx.doi.org/10.2307/1928445

Blanchard, O. J., \& Quah, D. (1989). The dynamic effects of aggregate demand and supply disturba. The American Economic Review, 79(4), 655-673.

Blinder, A. S. (1997). Is there a core of practical macroeconomics that we should all believe?. American Economic Review, 87(2), 240-243.

Brun-Aguerre, R., Fuertes, A., \& Phylaktis, K. (2012). Exchange rate pass-through into import prices revisited: What drives it?. Journal of International Money and Finance, 31(4), 818-844. http://dx.doi.org/10.1016/j.jimonfin.2012.01.009

Büttner, D., \& Hayo, B. (2012). EMU-related news and financial markets in the czech republic, hungary and poland. Applied Economics, 44(31), 4037-4053. http://dx.doi.org/10.1080/00036846.2011.587775

Cheng, M. Y., \& Tan, H. B. (2002). Inflation in Malaysia. International Journal of Social Economics, 29(5), 411-425. http://dx.doi.org/10.1108/03068290210423532

Cogley, T., \& Sbordone, A. M. (2008). Trend inflation, indexation, and inflation persistence in the new keynesian phillips curve. The American Economic Review, 98(5), 2101-2126. http://dx.doi.org/10.1257/aer.98.5.2101

Colletaz, G., \& Hurlin, C. (2006). Threshold effects in the public capital productivity: an international panel smooth transition approach. Document de Recherche du Laboratoire d'Economie d'Orleans.2006-1.

Doh, T. (2011). Is unemployment helpful in understanding inflation?. Economic Review - Federal Reserve Bank of Kansas City, 5-26.

Gachet, I., Maldonado, D., \& Perez, W. (2008). Determinants of inflation in a dollarized economy: The Case of Ecuador. Cuestiones Economicas, 24(1), 5-28.

Gerlach, S., \& Yiu, M. S. (2004). Estimating output gaps in Asia: A cross-country study. Journal of the Japanese and International Economies, 18, 115-136. http://dx.doi.org/10.1016/S0889-1583(03)00033-9

Ghironi, F., \& Giavazzi, F. (1998). Currency areas, international monetary regimes, and the employment-inflation tradeoff. Journal of International Economics, 45(2), 259-296. http://dx.doi.org/10.1016/S0022-1996(98)00029-4

Gonzalez, A., Teräsvirta, T., \& van Dijk, D. (2005). Panel smooth transition regression models. Research Paper Series 165 Quantitative Finance Research Centre. Sydney: University of Technology.

Goodman, D. E., \& McMahon, W. W. (1979). Predicting inflation rates with changing oil prices. Quarterly Review of Economics and Finance, 19(2), 35.

Granger, G. W. J., \& Teräsvirta, T. (1993). Modelling nonlinear economic relationships. Oxford University Press.

Hansen, B. E. (1999). Threshold effects in non-dynamic panels: Estimation, testing and inference. Journal of Econometrics, 93, 345-368. http://dx.doi.org/10.1016/S0304-4076(99)00025-1

Haque, N. U., \& Qayyum, A. (2006). Inflation everywhere is a monetary phenomenon: An introductory note. The Pakistan Development Review, 45(2), 179-183.

Im, K. S., Pesaran, M. H., \& Shin, Y. (2003). Testing for unit roots in heterogeneous panels. Journal of Econometrics, 115(1), 53-74. http://dx.doi.org/10.1016/S0304-4076(03)00092-7

Jacobs, R. L., \& Jones, R. A. (1980). Price expectations in the United States: 1947-75. The American Economic Review, 70(3), 269-269.

Kemal, M. A. (2006). Is inflation in Pakistan a monetary phenomenon?. Pakistan Development Review, 45, 213-220.

Levin, A., \& Lin, C. J. (1992). Unit root tests in panel data: asymptotic and finite sample properties. Discussion Paper, University of California, San Diego, May.

Levin, A., \& Lin, C. J. (1993). Unit root tests in panel data: new results. Discussion Paper, University of California, San Diego, December.

Levin, A., Lin, C., \& Chu, C. J. (2002). Unit root tests in panel data: asymptotic and finite-sample properties. Journal of Econometrics, 108(1), 1-24. http://dx.doi.org/10.1016/S0304-4076(01)00098-7 
Liu, D., \& Jansen, D. W. (2011). Does a factor Phillips curve help? an evaluation of the predictive power for U.S. inflation. Empirical Economics, 40(3), 807-826. http://dx.doi.org/10.1007/s00181-010-0352-0

Mallick, S. K., \& Mohsin, M. (2010). On the real effects of inflation in open economies: Theory and empirics. Empirical Economics, 39(3), 643-673. http://dx.doi.org/10.1007/s00181-009-0328-0

Mallik, G., \& Chowdhury, A. (2011). Effect of inflation uncertainty, output uncertainty and oil price on inflation and growth in Australia. Journal of Economic Studies, 38(4), 414-429. http://dx.doi.org/10.1108/01443581111160879

Matheson, T. D. (2008). Phillips curve forecasting in a small open economy. Economics Letters, 98(2), 161-166. http://dx.doi.org/10.1016/j.econlet.2007.04.025

McGuire, R. A., \& Willman, E. S. (1999). Textbook explanations of inflation in the 1970s. Public Finance Review, 27(1), 52-76. http://dx.doi.org/10.1177/109114219902700103

Meltzer, A. H. (2006). From inflation to more inflation, disinflation, and low inflation. The American Economic Review, 96(2), 185-188. http://dx.doi.org/10.1257/000282806777211900

Mullineaux, D. J. (1980). Inflation expectations and money growth in the united states. The American Economic Review, 70(1), 149-149. http://dx.doi.org/10.2307/1924741

Ormerod, P., Rosewell, B., \& Phelps, P. (2013). Inflation/unemployment regimes and the instability of the Phillips curve. Applied Economics, 45(12), 1519-1531. http://dx.doi.org/10.1080/00036846.2011.628299

Owen, A. L., \& Palmer, B. (2012). Macroeconomic conditions and technical trading profitability in foreign

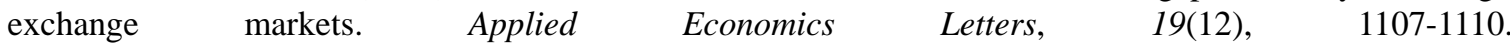
http://dx.doi.org/10.1080/13504851.2011.615723

Phillips, W. A. (1958). The relationship between unemployment and the rate of change of money wages 1862-1957. Economica, 34, 254-281.

Popovic, G. (2010). Inflation and unemployment: Phillips regularity in the EU. Sarajevo Business and Economics Review, 30, 370-389.

Razin, A., \& Yuen, C. W. (2002). The new Keynesian Phillips curve: closed economy versus open economy. Economics Letters, 75, 1-9. http://dx.doi.org/10.1016/S0165-1765(01)00588-2

Ribba, A. (2006). The joint dynamics of inflation, unemployment and interest rate in the united states since 1980. Empirical Economics, 31(2), 497-511. http://dx.doi.org/10.1007/s00181-005-0031-8

Roeger, W. (2005). International oil price changes: Impact of oil prices on growth and inflation in the EU/OECD. International Economics and Economic Policy, 2(1), 15-32. http://dx.doi.org/10.1007/s10368-005-0027-z

Stock, J. H., \& Watson, M. W. (1999). Forecasting inflation. Journal of Monetary Economics, 44(2), 293-335. http://dx.doi.org/10.1016/S0304-3932(99)00027-6

Tella, R. D., MacCulloch, R. J., \& Oswald, A. J. (2001). Preferences over inflation and unemployment: Evidence from surveys of happiness. The American Economic Review, 91(1), 335-341. http://dx.doi.org/10.1257/aer.91.1.335

Yilmazkuday, H. (2013). Inflation targeting, flexible exchange rates and inflation convergence. Applied Economics, 45(5), 593-603. http://dx.doi.org/10.1080/00036846.2011.608642

Zaman, K., Khan, M. M., Ahmad, M., \& Ikram, W. (2011). Inflation, unemployment and the NAIRU in Pakistan (1975-2009). International Journal of Economics and Finance, 3(1), 245-254. http://dx.doi.org/10.1258/ijsa.2011.010375

Zhou, S. (2013). Nonlinearity and stationarity of inflation rates: Evidence from the euro-zone countries. Applied Economics, 45(7), 849-856. http://dx.doi.org/10.1080/00036846.2011.613774

\section{Notes}

Note 1. Following Nieh (2002), a time-varying proxy for $\sigma_{\mathrm{t}}$ to measure the volatility can be specified as $\sigma_{i t}=\left[(1 / m) \sum_{i=1}^{m}\left(\log r o_{t+i-1}-\log r o_{t+i-2}\right)^{2}\right]^{0.5}$, where ro is the percentage change of the oil price, discount rate, and exchange rate $(i=1, \ldots, 7$ denotes the market and $t$ denotes the time period), and $m=3$, using seasonal considerations. 
Note 2. The United States is the home country, and we measured the exchange rates of each country as the effective exchange rate.

Note 3. The money supply is measured as M1 in each country.

Note 4. $\mathrm{m}=1$ corresponds to a logistic function with an $\mathrm{S}$-shape, and $\mathrm{m}=2$ corresponds to a exponential function with a U-shape.

Note 5. See González et al. (2005) or Colletaz and Hurlin (2006). 